\title{
Article \\ Improvement of Cognitive Function and Interleukin 1 Beta Serum Concentrations Following Cardiac Pacemaker Implantation in Patients with Symptomatic Bradycardia
}

\author{
Alexandru Martis ${ }^{1}\left(\mathbb{D}\right.$, Gabriel Gusetu ${ }^{1}$, Gabriel Cismaru ${ }^{1}\left[\right.$, Dumitru Zdrenghea ${ }^{1}$, Daniel-Corneliu Leucuta ${ }^{2, * \mathbb{C}}$ \\ and Dana Pop ${ }^{1}$ \\ 1 Rehabilitation Hospital Cardiology Department, "Iuliu Hatieganu" University of Medicine and Pharmacy, \\ 400347 Cluj-Napoca, Romania; alexandru_martis2387@yahoo.com (A.M.); gusetu@gmail.com (G.G.); \\ gabi_cismaru@yahoo.com (G.C.); dzdrenghea@yahoo.com (D.Z.); pop67dana@gmail.com (D.P.) \\ 2 Department of Medical Informatics and Biostatistics, "Iuliu Hatieganu” University of Medicine and \\ Pharmacy, 400349 Cluj-Napoca, Romania \\ * Correspondence: dleucuta@umfcluj.ro; Tel.: +40-264-597-256 (ext. 2502)
}

Citation: Martis, A.; Gusetu, G.; Cismaru, G.; Zdrenghea, D.; Leucuta, D.-C.; Pop, D. Improvement of Cognitive Function and Interleukin 1 Beta Serum Concentrations Following Cardiac Pacemaker Implantation in Patients with Symptomatic Bradycardia. J. Pers. Med. 2021, 11, 770. https://doi.org/10.3390/ jpm11080770

Academic Editor: Konstantinos Tziomalos

Received: 11 July 2021

Accepted: 3 August 2021

Published: 5 August 2021

Publisher's Note: MDPI stays neutral with regard to jurisdictional claims in published maps and institutional affiliations.

Copyright: (c) 2021 by the authors. Licensee MDPI, Basel, Switzerland. This article is an open access article distributed under the terms and conditions of the Creative Commons Attribution (CC BY) license (https:/ / creativecommons.org/licenses/by/ $4.0 /)$.

\begin{abstract}
Background and aim: Bradyarrhythmias cause a low cerebral blood flow with secondary neuronal ischemia and cognitive dysfunction. This study aims to assess the effect of cardiac pacemaker implantation (PI) on the cognitive function and inflammatory markers (TNF alpha, IL1 $\beta$ ). Material and method: We conducted a prospective observational study on a number of 31 patients with symptomatic bradyarrhythmias. We performed the cognitive function assessment by two tests (Mini-Mental State Examination and Trail Making Test A), cardiac output assessment (echocardiographic), and determination of IL $1 \beta$ and TNF alpha serum concentrations before pacemaker implantation and after an average period of 42 days from pacemaker implantation.Results: After pacemaker implantation we observed an increase in the cardiac index by $0.71 \mathrm{~L} / \mathrm{min} / \mathrm{m}^{2}(p<0.001)$ and a better scoring in cognitive performance; the mean MMSE score increased by two points $(p<0.001)$, and Trail Making Test A had an improvement of $16 \mathrm{~s}(p<0.001)$. Regarding the inflammatory markers, a significant decrease in IL-1 $\beta$ with $8.6 \mathrm{pg} / \mathrm{mL}(p=0.049)$ after pacemaker implantation was observed. Additionally, we found statistically significant correlations between IL1 $\beta$ and TNF alpha (positive correlation, $p=0.005)$, between the MMSE and cardiac index $(p<0.001)$, between the Trail Making Test and cardiac index $(p=0.001)$, and between the MMSE and Trail Making Test $(p=0.003)$. Conclusions: Our findings suggest that cardiac pacemaker implantation was associated with improved cognitive function-possibly related to an increased cardiac output and with adecreased serum IL1 $\beta$ concentration in subjects with symptomatic bradycardia.
\end{abstract}

Keywords: pacemaker; cognitive function; bradycardia; MMSE; trail making test; Interleukin 1 beta

\section{Introduction}

The prevalence of cognitive decline has continuously increased in the last 3 decades and is currently estimated at 19\% among the population over 65 years. Cognitive decline can be seen as a predetermined phase in which the subject still has functional independence. The severity of cognitive decline progresses over time in the absence of a specific treatment; around 120 subjects per 1000 people per year develop dementia [1-3].

Vascular dementia is the second cause for dementia after Alzheimer's disease and is caused by ischemia with different mechanisms of cerebral injury (microembolism, hypercoagulant status, endothelial dysfunction, reduced brain flow) [4,5].

Until now, few studies in the literature have evaluated the influence of pacemakers on improving cognitive parameters in patients with bradyarrhythmias, and we found no reports on the effects of cardiac pacemaker implantation on inflammatory markers (IL $1 \beta$ TNF alpha). In the last 10 years, some studies have confirmed that the cognitive decline 
prevalence increases simultaneously with the increase in the number of cardiovascular risk factors (heart failure, diabetes, hypertension, atrial fibrillation) [6].

Data about correlations between the cardiac output and cognitive decline have been highlighted, especially in patients with heart failure. Cognitive decline is influenced by the length of time and the severity of the decreased cardiac output [4].

Interleukin $1 \beta$ is considered to be involved in the development of dementia, being part of various acute and chronic inflammatory processes, and playing a key role in neuroinflammation and neuronal injury $[7,8]$.

Cardiac output is decreased in bradycardia due to a reduced heart rate, indirectly resulting in a decreased cerebral brain flow. Based on this hypothesis, we investigated whether the treatment of bradyarrhythmia by pacemaker implantation modifies cognitive parameters and inflammatory markers.

\section{Material and Methods}

\subsection{Study Design and Settings}

This is a prospective observational study that included 31 subjects with bradyarrhythmia. We investigated the cognitive function, cardiac output, and inflammatory markers, which were assessed before and after implantation of the cardiac pacemaker at an average period of 42 days.

Patients were hospitalized in the Cluj-Napoca Rehabilitation Hospital, Cardiology Department, Romania, all of them being diagnosed with bradyarrhythmia by EKG or Holter EKG. Their main complaints were syncope, dizziness, loss of balance, visual disturbances, and decreased exercise tolerance. Indication for pacemaker implantation (PI) was following current guidelines (Cardiac Pacing and Cardiac Resynchronization Therapy Guidelines issued by the European Society of Cardiology).

Evaluation of the patients was performed before and after the PI and consisted of 3 parts:

(1) The cognitive assessment, for which we used the psychometric scales Mini-Mental State Examination and Trail Making Test A.

(2) Calculation of cardiac output estimated by echocardiography.

(3) Evaluation of serum concentration of Interleukin $1 \beta$ and TNF alpha.

All cardiac pacemakers implanted were rate-adaptive with pacing rates between 60 beats/min and 130 beats/min depending on the mobilization of the patient.

\subsection{Participants}

Our study included patients with symptomatic bradyarrhythmia with an indication for pacemaker implantation according to ESC guidelines, at least 8 years of school education, and ejection fraction over $40 \%$.

Exclusion criteria were: dementia, severe valvulopathies, heart failure NYHA III or IV, history of stroke, severe carotid stenosis, advanced chronic renal failure, sensory deficits that made cognitive examination impossible, psychiatric disorders (dementia, alcoholism), or any form of neurodegenerative disease.

All patients signed the informed consent, and the study protocol was approved by the institution's Ethics and Research Committee (approval registration number 2605/04.04.2018).

\subsection{Evaluation of Parameters}

By echocardiography, we obtained cardiac index (CI) by measuring the left ventricle outflow tract (LVOT) diameter, LVOT velocity time integral (VTI) using pulse-wave Doppler, and heart rate, applying a specific formula adjusted to the body surface. Results of this non-invasive method have a strong correlation with measurements obtained by invasive methods such as pulmonary artery catheter thermodilution technique [9]. CI values below $1.9 \mathrm{~L} / \mathrm{min} / \mathrm{m}^{2}$ define the low cardiac output [10].

Blood samples for IL-1 $\beta$ and TNF alpha were collected in the morning, then rested for $15 \mathrm{~min}$ in specific vacutainers. The samples arrived within $30 \mathrm{~min}$ at the Hospital 
Laboratory, where they were centrifuged, followed by freezing the serum at -80 degrees Celsius. Serum level was measured by ELISA using Elisa Kit with Pre-Coated Plates Legend Max Lot No. B238395, the limit of detection being $0.01 \mathrm{pg} / \mathrm{mL}$ for IL- $1 \beta$ and $0.1 \mathrm{pg} / \mathrm{mL}$ for TNF alpha.

Cognitive tests were performed in a quiet environment, without noise or other disruptive factors. Cognitive function was assessed by a single investigator throughout the study. The Mini-Mental State Examination (MMSE) is a questionnaire that is extensively used in clinical and research settings to measure cognitive impairment (any impairment in perceptual, learning, memory, linguistic, or thinking abilities). It contains a set of questions that assess the patient's ability for temporospatial orientation, attention, memory, language, and calculation, with a maximum score of 30 points. Scores below 25 points define cognitive impairment with a sensitivity of $87 \%$ and specificity of $82 \%$ [11]. The Trail Making Test $\mathrm{A}$ is a neuropsychological test that evaluates visual attention and executive function, processing speed, and mental flexibility. The test requires a subject to connect in the shortest possible time a sequence of 25 consecutive targets on a sheet of paper. The normal range to complete the test varies according to the patient's age, being on average between 30 and $38 \mathrm{~s}$, a value over $78 \mathrm{~s}$ is considered being abnormal [12]. TMT A exhibits a sensitivity of $77 \%$ and specificity of $92 \%$ in screening for cognitive impairment [13].

The reason why we chose to evaluate the cognitive function with MMSE and TMT A tests was that they are simple to apply by any practitioner, with good specificity and sensitivity $(>80 \%)$ [14]. Another reason is that these tests are easy to understand by persons with low educational levels. In our study, the majority of them had between 8 and 12 years of education.

The assessments described above were performed before PI and repeated at a mean period of 42 days after the procedure.

\subsection{Statistical Analysis}

Categorical data were presented as absolute and relative frequencies. Quantitative data were presented as means and standard deviations when normally distributed, and as medians and interquartile ranges when non-normally distributed. Comparisons for repeated measures of non-normally distributed quantitative data were performed with the Wilcoxon test for repeated measures. The correlation coefficient for repeated measures, along with $95 \%$ bootstrapped confidence intervals and $p$-values, were computed with rmcorr package [15].

For all statistical tests, two-tailed $p$-values were computed, and a 0.05 level of significance was used.

All analyses were computed in R software (The R Foundation for Statistical Computing, Vienna, Austria), version 4.0.3 [16].

\section{Results}

Baseline characteristics are shown in Table 1 . The mean age was 70 years, the majority being male (61\%). Hypertension was the most common risk factor, encountered in $87 \%$ of participants. Body mass index (BMI) was $28 \mathrm{~kg} / \mathrm{m}^{2}, 80 \%$ of the subjects being with a high BMI.

The mean follow-up time was 42 days; $32 \%$ of subjects had at least one episode of syncope. A high degree atrioventricular block was the most common indication for pacemaker implantation, followed by atrial fibrillation with a slow ventricular rate. The most commonly implanted type of pacemaker was the VVIR.

Before the pacemaker implantation (PI), $25 \%$ of the subjects had a mild cognitive deficit (MMSE < 25 points). After PI, only $6.4 \%$ remained with an MMSE score suggestive for cognitive impairment. Regarding the TMT A score, $51 \%$ of the subjects had abnormal values (TMT A > 78 s), after PI, only $38 \%$ remained with abnormal values.

The mean pacing capture was $89.5 \%$. At the follow-up examination, 30 patients presented the parameters of pacemaker function within normal limits. One subject presented 
a pacing deficit that appeared on day 7 after the implantation procedure, presenting $1 \%$ pacing capture from total heartbeats. This patient did not show any improvement of the cognitive function (MMSE score 25 points, while the TMT A test showed a worsening result from $154 \mathrm{~s}$ to $170 \mathrm{~s})$.

After the implantation of the cardiac pacemaker, an increase in mean HR from $51 \mathrm{~b} / \mathrm{min}$ to $65 \mathrm{~b} / \mathrm{min}$ was observed with a concomitant increase in cardiac index by $0.71 \mathrm{~L} / \mathrm{min} / \mathrm{m}^{2}$. Prior to implantation, $90.3 \%$ of subjects had a cardiac index $(\mathrm{CI})<1.9 \mathrm{~L} / \mathrm{min} / \mathrm{m}^{2}$; after implantation, only $45.2 \%$ of subjects remained with a low CI (Table 2 ).

Table 1. Baseline characteristics.

\begin{tabular}{|c|c|}
\hline Characteristic & Number $(\%)(n=31) /$ Median(IQR) \\
\hline Age (years), mean (SD) & $70.87(6.95)$ \\
\hline Sex (F vs. M) & $12(38.71)$ \\
\hline Follow-up (days), median (IQR) & $42(38-44)$ \\
\hline $\mathrm{BMI}\left(\mathrm{kg} / \mathrm{m}^{2}\right)$, median $(\mathrm{IQR})$ & $28.68(24.58-32.67)$ \\
\hline SBP (mmHg), median (IQR) & $125(120-137.5)$ \\
\hline DBP (mmHg), median (IQR) & $75(70-80)$ \\
\hline \multicolumn{2}{|l|}{ Blood tests } \\
\hline Uric Acid, median (IQR) & $6.2(5.24-7.58)$ \\
\hline Total Cholesterol, median (IQR) & $177(148.5-200.5)$ \\
\hline High Density Cholesterol (mg/dL), median (IQR) & $40(35.5-50.5)$ \\
\hline Low Density Cholesterol (mg/dL), median (IQR) & $108(86-125)$ \\
\hline Triglycerides (mg/dL) (median (IQR) & $103(88-136)$ \\
\hline Creatinine $(\mathrm{mg} / \mathrm{dL})$, median $(\mathrm{IQR})$ & $0.99(0.82-1.14)$ \\
\hline Blood Sugar (mg/dL), median (IQR) & $93(88-102.75)$ \\
\hline Serum Potassium (mmol/L) median (IQR) & $4.4(3.79-4.67)$ \\
\hline Serum Sodium (mmol/L), median (IQR) & $141(140-142.5)$ \\
\hline Urea $(\mathrm{mg} / \mathrm{dL})$, median (IQR) & $38(33.5-46)$ \\
\hline Hemoglobin (g/dL), median (IQR) & $13.5(11.95-14.9)$ \\
\hline Hematocrit $(\%)$, median (IQR) & $40(36.45-44.3)$ \\
\hline White Blood Cells, median (IQR) & $6.5(5.8-7.61)$ \\
\hline Neutrophils, median (IQR) & $61.5(53.85-66.3)$ \\
\hline Erythrocyte Sedimentation Rate, median (IQR) & $15.5(9.25-25.5)$ \\
\hline Syncope & $10(32.2)$ \\
\hline History of Arterial Hypertension & $27(87)$ \\
\hline Diabetes & $6(19.3)$ \\
\hline Smoke & $9(29)$ \\
\hline \multicolumn{2}{|l|}{ Type of arrhythmia } \\
\hline Atrioventricular block: & $11(35.48)$ \\
\hline Sick sinus node syndrome with sinus bradycardia: & $7(22.5)$ \\
\hline Tachy-brady syndrome: & $3(9.6)$ \\
\hline Atrial fibrillation with low heart rate: & $10(32.2)$ \\
\hline \multicolumn{2}{|l|}{ * Type of pacemaker implanted } \\
\hline VVIR & $19(61.2)$ \\
\hline DDDR & $2(6.6)$ \\
\hline AAIR & $10(32.2)$ \\
\hline Pacing (\%) & $89.5(74.6-97.6)$ \\
\hline \multicolumn{2}{|l|}{ Cognitive assessments } \\
\hline MMSE $<25$ points & $8(25.8)$ \\
\hline TMT $\mathrm{A}>78 \mathrm{~s}$ & $16(51.6)$ \\
\hline
\end{tabular}


Table 2. Characteristics in dynamics.

\begin{tabular}{|c|c|c|c|c|}
\hline Variables & Before PI & After PI & $\begin{array}{l}\text { Absolute Difference } \\
\qquad(95 \% \text { CI })\end{array}$ & $p$-Value \\
\hline Heart Rate (beats /min), median (IQR) & $51(47.5-60)$ & $65(60-70)$ & $14(12.5-17.5)$ & $<0.001$ \\
\hline Stroke Volume $\left(\mathrm{mL} / \mathrm{m}^{2}\right)$, median (IQR) & $48.25(38.93-61.32)$ & $54.48(46.83-62.83)$ & $6.22(4.81-12.7)$ & $<0.001$ \\
\hline Cardiac Output (L/min), median (IQR) & $2.65(1.86-3.03)$ & $3.71(2.81-4.09)$ & $1.05(0.87-1.27)$ & $<0.001$ \\
\hline Cardiac Index $\left(\mathrm{L} / \mathrm{min} / \mathrm{m}^{2}\right)$, median (IQR) & $1.21(0.97-1.58)$ & $1.92(1.53-2.02)$ & $0.71(0.46-0.69)$ & $<0.001$ \\
\hline Trail Making Test A, median (IQR) & $78(60.23-122)$ & $62(42-96)$ & $16(13.75-27.5)$ & $<0.001$ \\
\hline Mini Mental State Examination, median (IQR) & $27(24.25-29)$ & $29(27.25-30)$ & $2(2-3.5)$ & $<0.001$ \\
\hline TNF Alfa (pg/mL), median (IQR) & $31.5(0-48.75)$ & $34(0.25-53)$ & $2.5(-38.5-30.5)$ & 0.859 \\
\hline IL- $1 \beta(\mathrm{pg} / \mathrm{mL}$, median (IQR) & $15.45(2.42-30)$ & $6.85(1.12-13.12)$ & $8.6(0-15.2)$ & 0.049 \\
\hline
\end{tabular}

IQR—interquartile range; CI—confidence interval; PI—Pacemaker implantation; TNF alpha—Tumor Necrosis Factor Alpha; IL-1 $\beta$ Interleukin 1 Beta.

Cognitive assessment after PI found better MMSE scores with a mean increase from 27 points to 29 points. Additionally, the time to complete the TMT A test was reduced by a mean of $16 \mathrm{~s}$ (Table 2). At the same time, a positive correlation was observed between the increase in CO and the improvement of the MMSE score, respectively, the increase in CI and the decrease in TMT A values, as well as a correlation between the improvement of the MMSE score and TMT A values (Table 3, Figure 1).

Serum IL $1 \beta$ concentrations decreased after PI by a mean of $8.6 \mathrm{pg} / \mathrm{mL}$, resulting with a statistical significance $(p=0.049)$ (Table 2$)$. We did not find any statistically significant differences regarding TNF alpha concentrations, but we noticed a positive correlation between concentrations of IL1 $\beta$ and TNF alpha $(p=0.005)$ (Figure 1$)$.

Table 3. Correlation analyses for cognitive function and inflammatory markers.

\begin{tabular}{|c|c|c|c|c|c|}
\hline & $\begin{array}{l}\text { TNF Alpha } \\
\text { (pg/mL) }\end{array}$ & $\operatorname{IL1} \beta(\mathrm{pg} / \mathrm{mL})$ & MMSE & $\begin{array}{l}\text { Cardiac Index } \\
\left(\mathrm{L} / \mathrm{min} / \mathrm{m}^{2}\right)\end{array}$ & TMT A \\
\hline $\begin{array}{l}\text { TNF Alpha } \\
\text { (pg/mL) }\end{array}$ & 1 & $\begin{array}{c}0.49(0.21-0.73) \\
0.005\end{array}$ & $\begin{array}{c}-0.27(-0.55-0.15) \\
0.139\end{array}$ & $\begin{array}{c}-0.21(-0.49-0.24) \\
0.27\end{array}$ & $\begin{array}{c}0.12(-0.19-0.43) \\
0.524\end{array}$ \\
\hline $\operatorname{IL} 1 \beta(\mathrm{pg} / \mathrm{mL})$ & $\begin{array}{c}0.49(0.23-0.74) \\
0.005\end{array}$ & 1 & $\begin{array}{c}-0.23(-0.62-0.19) \\
0.204\end{array}$ & $\begin{array}{c}-0.22(-0.59-0.11) \\
0.235\end{array}$ & $\begin{array}{c}0.23(-0.19-0.57) \\
0.213\end{array}$ \\
\hline MMSE & $\begin{array}{c}-0.27(-0.62-0.13) \\
0.139\end{array}$ & $\begin{array}{c}-0.23(-0.64-0.12) \\
0.204\end{array}$ & 1 & $\begin{array}{c}0.72(0.6-0.83) \\
\quad<0.001\end{array}$ & $\begin{array}{c}-0.51(-0.87-0.34) \\
0.003\end{array}$ \\
\hline $\begin{array}{l}\text { Cardiac Index } \\
\left(\mathrm{L} / \mathrm{min} / \mathrm{m}^{2}\right)\end{array}$ & $\begin{array}{c}-0.21(-0.54-0.16) \\
0.27\end{array}$ & $\begin{array}{c}-0.22(-0.58-0.11) \\
0.235\end{array}$ & $\begin{array}{c}0.72(0.61-0.82) \\
<0.001\end{array}$ & 1 & $\begin{array}{c}-0.62(-0.89-0.47), \\
<0.001\end{array}$ \\
\hline TMT A & $\begin{array}{c}0.12(-0.15-0.33) \\
0.524\end{array}$ & $\begin{array}{c}0.23(-0.25-0.57) \\
0.213\end{array}$ & $\begin{array}{c}-0.51(-0.89-0.38) \\
0.003\end{array}$ & $\begin{array}{c}-0.62(-0.87-0.52) \\
<0.001\end{array}$ & 1 \\
\hline
\end{tabular}

IQR—interquartile range; CI—confidence interval; PI—pacemaker implantation; TNF alpha—Tumor Necrosis Factor Alpha; IL-1 $\beta$ Interleukin 1 Beta; MMSE-Mini Mental State Examination; TMT A-Trail Making Test A;CO-Cardiac Output. Data are presented as correlation coefficient ( $95 \%$ bootstrapped confidence interval), $p$-value. 

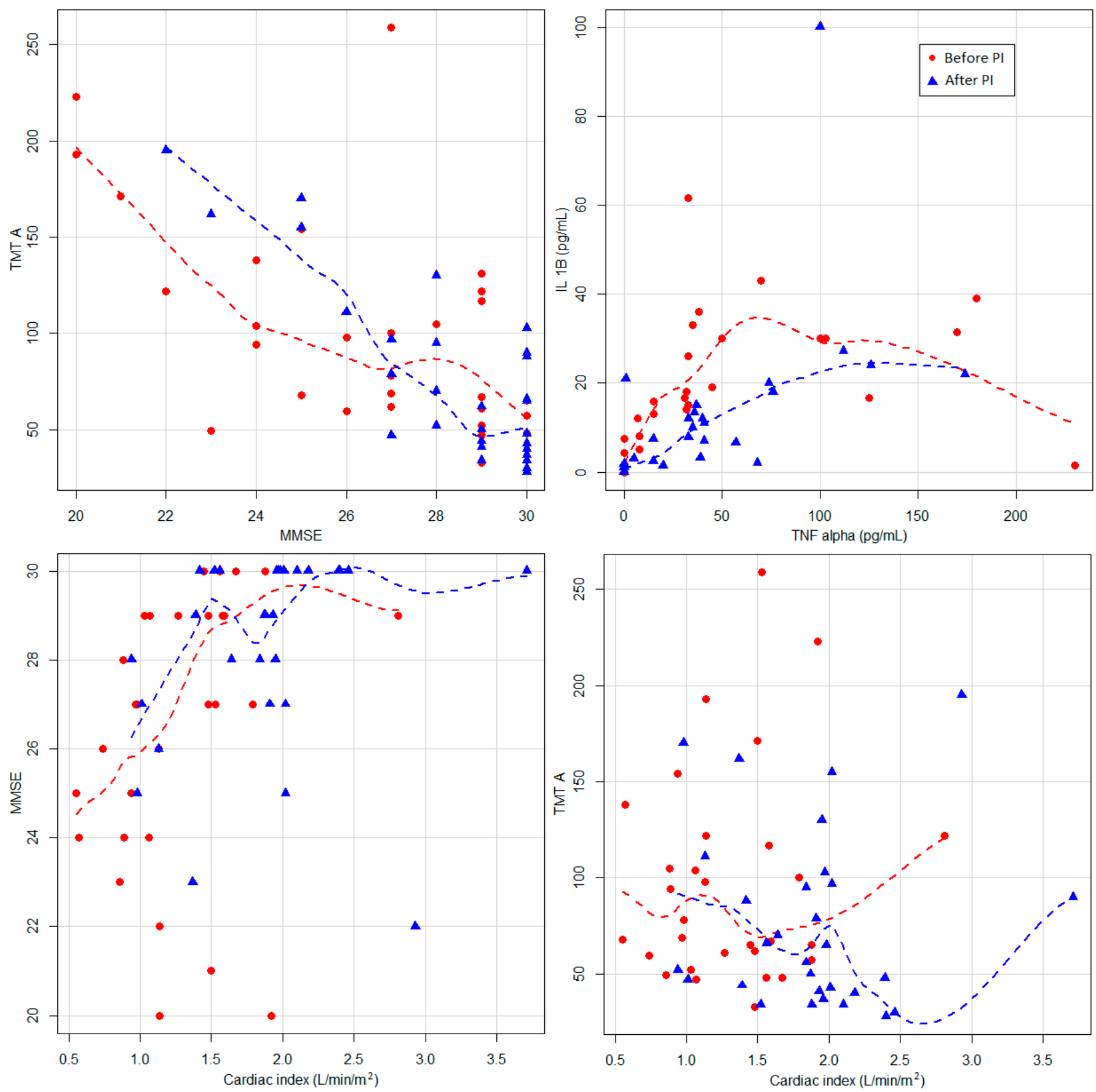

Figure 1. Relation between cardiac index and MMSE and TMT A. The lines represent locally weighted scatterplot smoothing curves. MMSE-Mini Mental State Examination; TMT A-Trail Making Test A; PI—pacemaker implantation; TNF alpha— Tumor Necrosis Factor Alpha; IL-1 $\beta$-Interleukin 1 Beta.

\section{Discussion}

The results of this prospective study suggest that, following pacemaker implantation, there is an increase in cardiac output, improvements of cognitive function, and a decrease in IL $1 \beta$ serum concentrations. We also found a positive correlation between an increased cardiac output and improvement of cognitive parameters, as well as a correlation between IL1 $\beta$ and TNF alpha. The data suggest that symptomatic bradycardia causes low cerebral perfusion, cerebral self-regulation being insufficient in long-term chronic hypoperfusion [18]. Chronic hypoperfusion consequences in patients with bradycardia 
were impaired cognitive function and the activation of the inflammatory immune system. Treatment of bradyarrhythmia by PI not only determines an increased heart rate, but also improves cognitive function and decreases serum IL1 $\beta$ levels.

Data from the literature are few. There are several studies that highlight the presence of a cognitive decline in cardiac pacemaker patients without objectifying whether or not pacemaker implantation brings improvements in cognitive functions $[19,20]$. Our study is the first study that evaluates IL- $1 \beta$ serum concentrations related to cardiac pacemaker implantation.

Efimova et al. assessed cognitive function after pacemaker implantation in a small group (17 patients), having a low $\mathrm{CO}$ caused by atrial fibrillation with a high ventricular rate and which required atrioventricular node ablation and PI. The study founded favorable results related to the improvement of cerebral perfusion and cognitive performance [21].

Another study by Hiromi Koide et al. on a group of 14 subjects observed an increase in cardiac output by $0.8 \mathrm{~L} / \mathrm{min}$, with a similar result to our study where the increase in flow was $1.05 \mathrm{~L} / \mathrm{min}$. They also observed improvements in cognitive functions by applying the Wechsler Memory Scale and Block Design Test [22].

A similar study that used TMT found that a low cardiac output $<4 \mathrm{~L} / \mathrm{min}$ was associated with cognitive dysfunction and a poor performance on performing TMT A. In our study, $90 \%$ had DC $<4 \mathrm{~L} / \mathrm{min}$, and $51 \%$ of them had abnormal TMT A values [18].

IL-1 $\beta$ beta normal range in the healthy population is between 0.5 and $12 \mathrm{pg} / \mathrm{mL}$. The mean value in our study was slightly increased $(15.45 \mathrm{pg} / \mathrm{mL})$, decreasing at $6.85 \mathrm{pg} / \mathrm{mL}$ after pacemaker implantation $(p=0.049)[8,23]$. The INCHIANTI study, which included the evaluation of 1292 participants of serum IL $1 \beta$ values, found correlations between cardiac output, cognitive function, and IL $1 \beta$ values; our study indirectly confirming these results [24]. We did not find any studies regarding the impact of PI on Interleukin $1 \beta$ serum concentrations. Our study suggests there is a link between the improvement of cerebral perfusion by the PI and inflammatory response. A similar study exists related to the decreased expression of IL- $1 \beta$-responsible genes in a group of patients with cardiac resynchronization therapy responders [23].

The possible confounders for IL-1beta, TNF-alpha were represented by chronic pathologies that influence the inflammatory status: chronic infections, chronic autoimmune disorders, diabetes, neoplasms, but as they were present before and after implantation, their impact was more likely to be low, a higher variation of the inflammatory marker values might have been induced by acute decompensations of these chronic conditions, and some of these might even not be identified. The implantation of the pacemaker comes with the possible risk of pocket infections, or an inflammatory response to the device, which would increase the values of inflammatory markers. Possible confounders for psychological status (MMSE, TMT A) were represented: age, history of hypertension, heart failure, atrial fibrillation, alcohol consumption, hypoxemia secondary to severe chronic obstructive pulmonary disease, sleep apnea syndrome, asthma, syncope, stroke, neurodegenerative disease (dementia), and psychiatric disorders. Some of these were excluded during the patient selection process. The majority are chronic conditions, that were present both before and after pacemaker implantation; thus, likely having a low effect on the measured variables.

There were some limitations of this study. The most important was the fact that the study design was observational, non-randomized, and without a control group, which implies that confounding could be an important issue. This type of methodology allowed us only to control the possible confounders by excluding some of them during the selection of the subjects for the study (dementia, psychiatric disorders (dementia, alcoholism), or any form of neurodegenerative disease; severe valvopathies, heart failure NYHA III or IV, history of stroke, severe carotid stenosis, advanced chronic renal failure). The before-after design that focused the comparisons on the intraindividual scope limited the stable chronic conditions effects on the measured outcomes. However, residual confounding or external influences might still be an issue. The before-after design can lead to internal selection bias, can be subject to secular trends (that cannot be identified), or the regression to the 
mean effect, or other external influences on the study participants, including lifestyle changes and the Hawthorne effect. Another limitation of the study was its small sample size. Nevertheless, this study had one of the largest sample sizes compared to other studies in the literature $[22,25-28]$.

\section{Conclusions}

Our study observed that after pacemaker implantation in patients with symptomatic bradycardia, there was a statistically significant increase in the cardiac output, an improvement of cognitive functions (higher MMSE scores, shorter Trail Making Test A time), and a decrease in serum IL $1 \beta$ concentrations. We also observed a statistically significant direct proportional relation between the cardiac index and positive results of cognitive tests (TMT A, MMSE).

Author Contributions: Conceptualization, A.M., D.P.; investigation, A.M.; formal analysis, D.-C.L.; resources, G.G., G.C. and D.Z.; writing—original draft preparation, A.M.; writing—review and editing, A.M., D.-C.L. and D.P.; project administration, A.M.; funding acquisition, A.M. and D.P. All authors have read and agreed to the published version of the manuscript.

Funding: This research received no external funding.

Institutional Review Board Statement: The study was conducted according to the guidelines of the Declaration of Helsinki and approved by the Rehabilitation Hospital Cardiology Department Ethics and Research Committee (approval registration number 2605/04.04.2018).

Informed Consent Statement: Informed consent was obtained from the subject involved in the study.

Data Availability Statement: Data available on request due to restrictions e.g., privacy and ethical.

Conflicts of Interest: The authors declare no conflict of interest.

\section{References}

1. Rodríguez-Sánchez, E.; Mora-Simón, S.; Patino-Alonso, M.C.; García-García, R.; Escribano-Hernández, A.; García-Ortiz, L.; Bartolomé, M.V.P.; Gómez-Marcos, M.A. Prevalence of cognitive impairment in individuals aged over 65 in an urban area: DERIVA study. BMC Neurol. 2011, 11, 147. [CrossRef]

2. Langa, K.M.; Levine, D.A. The Diagnosis and Management of Mild Cognitive Impairment: A Clinical Review. JAMA 2014, 312, 2551-2561. [CrossRef]

3. Plassman, B.L.; Langa, K.M.; Ba, R.J.M.; Fisher, G.G.; Potter, G.G.; Burke, J.R.; Steffens, D.C.; Foster, N.L.; Giordani, B.; Unverzagt, F.W.; et al. Incidence of dementia and cognitive impairment, not dementia in the united states. Ann. Neurol. 2011, 70, 418-426. [CrossRef] [PubMed]

4. Zuccalá, G.; Marzetti, E.; Cesari, M.; Monaco, R.L.; Antonica, L.; Cocchi, A.; Carbonin, P.; Bernabei, R. Correlates of cognitive impairment among patients with heart failure: Results of a multicenter survey. Am. J. Med. 2005, 118, 496-502. [CrossRef] [PubMed]

5. Abete, P.; DELLA Morte, D.; Gargiulo, G.; Basile, C.; Langellotto, A.; Galizia, G.; Testa, G.; Canonico, V.; Bonaduce, D.; Cacciatore, F. Cognitive impairment and cardiovascular diseases in the elderly. A heart-brain continuum hypothesis. Ageing Res. Rev. 2014, 18, 41-52. [CrossRef] [PubMed]

6. Luchsinger, J.A.; Reitz, C.; Honig, L.S.; Tang, M.-X.; Shea, S.; Mayeux, R. Aggregation of vascular risk factors and risk of incident Alzheimer disease. Neurology 2005, 65, 545-551. [CrossRef]

7. Holmes, C.; El-Okl, M.; Williams, A.L.; Cunningham, C.; Wilcockson, D.; Perry, V.H. Systemic infection, interleukin 1beta, and cognitive decline in Alzheimer's disease. J. Neurol. Neurosurg. Psychiatry 2003, 74, 788-789. [CrossRef]

8. O'Neill, C.M.; Lu, C.; Corbin, K.L.; Sharma, P.R.; Dula, S.B.; Carter, J.D.; Ramadan, J.W.; Xin, W.; Lee, J.K.; Nunemaker, C.S. Circulating Levels of IL-1B+IL-6 Cause ER Stress and Dysfunction in Islets From Prediabetic Male Mice. Endocrinology 2013, 154, 3077-3088. [CrossRef]

9. Zhang, Y.; Wang, Y.; Shi, J.; Hua, Z.; Xu, J. Cardiac output measurements via echocardiography versus thermodilution: A systematic review and meta-analysis. PLoS ONE 2019, 14, e0222105. [CrossRef] [PubMed]

10. Rusinaru, D.; Bohbot, Y.; Djelaili, F.; Delpierre, Q.; Altes, A.; Serbout, S.; Kubala, M.; Maréchaux, S.; Tribouilloy, C. Normative Reference Values of Cardiac Output by Pulsed-Wave Doppler Echocardiography in Adults. Am. J. Cardiol. 2021, 140, 128-133. [CrossRef] [PubMed]

11. Mini-Mental State Examination (MMSE) for the Detection of Dementia in People Aged over 65. Available online: https:// www.cochrane.org/CD011145/DEMENTIA_mini-mental-state-examination-mmse-detection-dementia-people-aged-over-65 (accessed on 28 July 2021). 
12. Tombaugh, T.N. Trail Making Test A and B: Normative data stratified by age and education. Arch. Clin. Neuropsychol. 2004, 19, 203-214. [CrossRef]

13. Wei, M.; Shi, J.; Li, T.; Ni, J.; Zhang, X.; Li, Y.; Kang, S.; Ma, F.; Xie, H.; Mingqing, W.; et al. Diagnostic Accuracy of the Chinese Version of the Trail-Making Test for Screening Cognitive Impairment. J. Am. Geriatr. Soc. 2018, 66, 92-99. [CrossRef]

14. Mitchell, A.J. A meta-analysis of the accuracy of the mini-mental state examination in the detection of dementia and mild cognitive impairment. J. Psychiatr. Res. 2009, 43, 411-431. [CrossRef] [PubMed]

15. Bakdash, J.Z.; Marusich, L. Repeated Measures Correlation. Front. Psychol. 2017, 8, 456. [CrossRef]

16. R: The R Foundation. Available online: https://www.r-project.org/foundation/ (accessed on 31 July 2021).

17. Modes of Cardiac Pacing: Nomenclature, Selection and Indications for Permanent Cardiac Pacing. The Cardiology Advisor. 2019. Available online: https://www.thecardiologyadvisor.com/home/decision-support-in-medicine/cardiology/modes-ofcardiac-pacing-nomenclature-selection-and-indications-for-permanent-cardiac-pacing/ (accessed on 28 July 2021).

18. Jefferson, A.L.; Poppas, A.; Paul, R.H.; Cohen, R.A. Systemic hypoperfusion is associated with executive dysfunction in geriatric cardiac patients. Neurobiol. Aging 2007, 28, 477-483. [CrossRef] [PubMed]

19. Cognitive Assessments in Patients with Implantable Cardiac Pacemaker. Available online: https: / / www.romanianjournalcardiology. ro/arhiva/cognitive-assessments-in-patients-with-implantable-cardiac-pacemaker/ (accessed on 6 June 2021).

20. Fowler, N.R.; Johnson, K.G.; Li, J.; Moore, C.G.; Saba, S.; Lopez, O.L.; Barnato, A.E. Use of Cardiac Implantable Electronic Devices in Older Adults With Cognitive Impairment. JAMA Intern. Med. 2014, 174, 1514-1516. [CrossRef]

21. Efimova, I.; Efimova, N.; Chernov, V.; Popov, S.; Lishmanov, Y. Ablation and Pacing: Improving Brain Perfusion and Cognitive Function in Patients with Atrial Fibrillation and Uncontrolled Ventricular Rates. Pacing Clin. Electrophysiol. 2011, 35, 320-326. [CrossRef] [PubMed]

22. Koide, H.; Kobayashi, S.; Kitani, M.; Tsunematsu, T.; Nakazawa, Y. Improvement of Cerebral Blood Flow and Cognitive Function following Pacemaker Implantation in Patients with Bradycardia. Gerontology 1994, 40, 279-285. [CrossRef]

23. Cardiac Resynchronization Therapy Reduces Expression of Inflammation-Promoting Genes Related to Interleukin-1 $\beta$ in Heart Failure-PubMed. Available online: https:/ / pubmed.ncbi.nlm.nih.gov/31612215/ (accessed on 7 June 2021).

24. Di Iorio, A. Serum IL-1 $\beta$ levels in health and disease: A population-based study. "The InCHIANTI study". Cytokine 2003, 22, 198-205. [CrossRef]

25. Rockwood, K.; Dobbs, A.R.; Rule, B.G.; Howlett, S.E.; Black, W.R. The Impact of Pacemaker Implantation on Cognitive Functioning in Elderly Patients. J. Am. Geriatr. Soc. 1992, 40, 142-146. [CrossRef]

26. White, M.; Tubbesing, S. Improvement in Cognitive Function Post Cardiac Pacemaker. Proc. UCLA Health 2018, $22,1-2$.

27. Barbe, C.; Puisieux, F.; Jansens, I.; Dewailly, P.; Klug, D.; Kacet, S.; DiPompeo, C. Improvement of Cognitive Function after Pacemaker Implantation in Very Old Persons with Bradycardia. J. Am. Geriatr. Soc. 2002, 50, 778-780. [CrossRef] [PubMed]

28. Dalessio, D.J.; Benchimol, A.; Dimond, E.G. Chronic encephalopathy related to heart block: Its correction by permanent cardiac pacemaker. Neurology 1965, 15, 499. [CrossRef] [PubMed] 